\title{
Millimeter wave radiation induces apoptosis via affecting the ratio of Bax/Bcl-2 in SW1353 human chondrosarcoma cells
}

\author{
XIHAI LI ${ }^{1}$, HONGZHI YE ${ }^{1}$, LIANGLIANG CAI ${ }^{2}$, FANGRONG YU $^{2}$, WENLIE CHEN $^{1}$, RUHUI LIN $^{2}$, \\ CHUNSONG ZHENG ${ }^{1}$, HUIFENG XU ${ }^{1}$, JINXIA YE ${ }^{2}$, GUANGWEN WU ${ }^{1}$ and XIANXIANG LIU ${ }^{1}$ \\ ${ }^{1}$ Academy of Integrative Medicine; ${ }^{2}$ Fujian Key Laboratory of Integrative Medicine on Geriatrics, \\ Fujian University of Traditional Chinese Medicine, Fuzhou 350108, P.R. China
}

Received October 1, 2011; Accepted November 7, 2011

DOI: 10.3892/or.2011.1558

\begin{abstract}
The efficacy and safety of millimeter wave radiation has been proven for various types of malignant tumors. However, the mechanisms underlying effects of millimeter wave radiation on apoptosis are still unclear. The present study was undertaken to examine the effects of millimeter wave radiation on cell apoptosis and mitochondrial membrane potential, and to determine the molecular mechanism of millimeter wave radiation-induced apoptosis by investigating the expression of Bcl-2 family proteins (Bcl-2, Bax), caspase-9 and caspase-3 in SW1353 cells. We found that millimeter wave radiation suppressed the viability of SW1353 cells, demonstrating that millimeter wave radiation induced cell apoptosis and reduced cell viability in a time-dependent manner. Furthermore, we observed that treatment of cells with millimeter wave radiation significantly induced loss of mitochondrial membrane potential, upregulated proapoptotic Bax, caspase- 9 and caspase-3, but did not significantly change levels of antiapoptotic Bcl-2. These data suggested that millimeter wave radiation may induce apoptosis via affecting the ratio of Bax/Bcl-2 in SW1353 cells.
\end{abstract}

\section{Introduction}

Millimeter wave, part of the electromagnetic spectrum, is considered to be the radiation ranging in frequency from 300 million cycles per second ( $300 \mathrm{MHz}$ ) to 300 billion cycles per second $(300 \mathrm{GHz})$, which correspond to a wavelength from 10 to $1 \mathrm{~mm}(1,2)$. The power density of this therapy used in medicine varies from 1 to $10 \mathrm{mw} / \mathrm{cm}^{2}$, and is applied in experimental and clinical oncology $(3,4)$. While it is well established that at high power densities, millimeter wave radiation induces thermal increase on the exposed biosystems whose

Correspondence to: Professor Xianxiang Liu, Academy of Integrative Medicine, Fujian University of Traditional Chinese Medicine, 1 Huatuo, University Town, Minhou Shangjie, Fuzhou 350108, P.R. China E-mail: liuxianxiang@163.com

Key words: apoptosis, millimeter wave radiation, mitochondria, chondrosarcoma mechanisms could be non-thermal and of resonant nature or at least frequency-specific (5). Previously studies demonstrated millimeter wave radiation in treatment for various types of malignant tumors. The main indications for this therapy are prevention of metastases, relapses, and dissemination of the tumor; prevention and treatment of side-effects and complications from chemotherapy and radiotherapy; and treatment of the paraneoplastic syndrome (6,7). However, the molecular mechanism of millimeter wave radiation therapeutic effect is not well understood.

Studies of biological effects caused by millimeter wave radiation have shown that it could selectively kill human tumor cells $(8,9)$. Apoptosis (programmed cell death), is an important biological phenomenon for it can be considered as an innate cellular response to eliminate abnormal, redundant, excess cells in mammal and hence is crucial for mammal development and tissue homeostasis. Apoptosis disturb regulation of this vital process representing a major causative factor in the pathogenesis of various types of cancers. Apoptosis is characterized by a number of cytological alterations, such as DNA fragmentation, chromatin condensation and activation of cysteinyl aspartate-specific proteinases - the caspases $(10,11)$. The pathways leading to apoptosis may be dependent on or independent of caspases, caspase-dependent apoptosis is a widely recognized phenomenon. The mitochondrion-dependent apoptotic pathway plays an important role in activation of caspases. The mitochondrial membrane permeabilization, accompanied by the collapse of electrochemical gradient across the mitochondrial membrane, serves as critical regulator of mitochondria in the control of apoptosis (12). Bcl-2 family proteins regulate apoptosis through their influence on the permeability of mitochondrial outer membrane (MOM) following hetero- or homo-association. It has been demonstrated that after activation, pro-apoptotic proteins such as Bax increase MOMP during apoptosis, releasing apoptogenic proteins including cytochrome $\mathrm{c}$ triggering apoptosis via activating caspases and nucleases; whereas anti-apoptotic proteins such as Bcl-2 may bind to active Bax to prevent it from damaging the MOM $(13,14)$. The regulation of activing pro- and anti-apoptotic Bcl-2 family proteins determines the fate of cells, and alteration of the ratio by aberrant expression of these proteins leads to disturbance of the normal apoptotic program contributing to various apoptosis-related diseases 
$(15,16)$. Therefore, induction of apoptosis through regulating the effect of Bcl-2 family proteins on the caspase-dependent apoptosis pathway has been the main focus in the development of anti-cancer therapies.

Previous studies have focused on the biological effects of millimeter wave radiation treated cancer $(17,18)$. In order to extend the clinical observations of the potential anti-cancer effect of a novel approach for physical therapy and help to establish a scientific foundation for further research, in this study, we evaluated the effect of millimeter wave radiation on the apoptosis of the human chondrosarcoma cell line SW1353, and investigated the possible molecular mechanisms mediating its biological effects. We found that millimeter wave radiation induced apoptosis of SW1353 cells was accompanied by loss of mitochondrial membrane potential $(\Delta \psi \mathrm{m})$, up-regulation of Bax, the ratio of Bax/Bcl-2, caspase- 9 and caspase-3 activation. Our data suggest that millimeter wave radiation promoted SW1353 cell apoptosis via regulation the ratio of $\mathrm{Bax} / \mathrm{Bcl}-2$, which probably is one of the mechanisms in the treatment of cancer.

\section{Materials and methods}

Materials and reagents. Fetal bovine serum (FBS), Dulbecco's modified Eagle's medium (DMEM), trypsin-EDTA and penicillin-streptomycin were obtained from Hyclone (Carlsbad, CA, USA). TRIzol reagent, 5,5',6,6'-tetrachloro-1,1',3,3'-tetraethylbenzimidazol-carbocyanine iodide (JC-1), bis-benzimidazole dye Hoechst 33258, caspase-9 and caspase-3 colorimetric protease assay kits were provided from Invitrogen (Grand Island, NY, USA). SuperScript II reverse transcriptase was obtained from Promega (Madison, WI, USA). Bcl-2, Bax and $\beta$-actin antibodies, horseradish peroxidase (HRP)conjugated secondary antibodies were purchased from Santa Cruz Biotechnology (CA, USA). Fluorescein isothiocyanate (FITC)-conjugated Annexin V apoptosis detection kit was provided by Becton-Dickinson (San Jose, CA, USA).

Cell culture. Human chondrosarcoma cell line SW1353 from Insitute of Biochemistry and Cell Biology, Chinese Academy of Sciences (Shanghai, China) was maintained at $37^{\circ} \mathrm{C}$ in humidified incubator with $5 \% \mathrm{CO}_{2}$ with DMEM, supplemented with $10 \%$ (v/v) FBS, penicillin $(100 \mathrm{U} / \mathrm{ml})$ and streptomycin $(100 \mu \mathrm{g} / \mathrm{ml})$. SW1353 cells were subcultured at $80-90 \%$ confluency and were detached using $0.25 \%$ Trypsin-EDTA solution. The cells used in this study were subjected to no more than 30 cell passages.

Millimeter wave radiation exposure. The stability of millimeter wave radiation used for cell exposure is a very important issue for the experiment. KFA-100A millimeter wave therapeutic instrument was manufactured by Zhongcheng Kangfu Technology Co.,Ltd.(Beijing, China). Wavelengths of 7.5-10.0 mm, a power density of $4 \mathrm{mw} / \mathrm{cm}^{2}$, and a radiation area of $45.6 \pm 4.0 \mathrm{~mm}$ long and $33.2 \pm 3.0 \mathrm{~mm}$ wide were used. The millimeter wave radiation was propagated from the bottom of the Petri dish, and the treatment head was placed at a distance $r$ sufficiently near to the Petri dish so that the radiation beam impinged the entire surface of the samples (Fig. 1). Thus, simultaneously to each millimeter wave radiation experiment, cells were placed at $37^{\circ} \mathrm{C}$ in a humidified incubator. Moreover, control cells were kept in the same experimental conditions, but they were not exposed to millimeter wave radiation.

Cell viability by MTT assay. The SW1353 cells were cultured in 96-well plates at a concentration of $1 \times 10^{4}$ cells/well for cell viability, and assessed by the MTT colorimetric assay. The cells were continuously treated with millimeter wave radiation for $15,30,60,90$ and $120 \mathrm{~min}$, respectively, and then cultured $24 \mathrm{~h}$. After treatment, $10 \mu \mathrm{l}$ MTT [5 $\mathrm{mg} / \mathrm{ml}$ in phosphate buffered saline (PBS)] was added to each well, and the cells were incubated at $37^{\circ} \mathrm{C}$ for $4 \mathrm{~h}$. The purple-blue MTT formazan precipitate was dissolved in $100 \mu \mathrm{l}$ DMSO and the cells were shaken for $10 \mathrm{~min}$. The absorbance was measured at $490 \mathrm{~nm}$ using an ELISA reader (BioTek, Model EXL800, USA).

Observation of morphologic changes. The cells were cultured in $35 \mathrm{~mm}$ Petri dish at a concentration of $5 \times 10^{4}$ cells. The cells were continuously treated with millimeter wave radiation for $15,30,60,90$ and $120 \mathrm{~min}$, and then cultured $24 \mathrm{~h}$. The cell morphology was observed using a phase-contrast microscope (Olympus, Japan). The photographs of SW1353 cells were taken at a magnification of $\times 100$.

Observation of apoptosis by fluorescent phase-contrast microscope with Hoechst 33258 staining. After treatment with or without millimeter wave radiation, the SW1353 cells were fixed in $4 \%$ neutral formaldehyde for $30 \mathrm{~min}$, washed with PBS for $5 \mathrm{~min}$, and stained with $10 \mu \mathrm{M}$ Hoechst 33258 at $37^{\circ} \mathrm{C}$ for $30 \mathrm{~min}$ in the dark. The bis-benzimidazole dye Hoechst 33258 exhibits high fluorescence upon binding to the double-stranded DNA. Nuclear shape and chromosomal structure can be visualized and counted by staining nuclear DNA with Hoechst 33258 in live and apoptotic cells by fluorescence microscopy. The photographs of cells were taken at a magnification of x100 under a fluorescent phase-contrast microscope.

Detection of apoptosis by flow cytometry analysis with Annexin V/PI staining. SW1353 cells were cultured in $35 \mathrm{~mm}$ Petri dish at a concentration of $5 \times 10^{4}$ cells. The cells treated with millimeter wave radiation for 60 and $90 \mathrm{~min}$, and then cultured for $24 \mathrm{~h}$. The apoptosis of SW1353 cells was determined by flow cytometry analysis using a fluorescenceactivated cell sorting (FACS)Calibur (Becton-Dickinson) with Annexin V-fluorescein isothiocyanate (FITC)/propidium iodide (PI) staining. Staining was performed according to the manufacturer's instructions. Early apoptotic cells were calculated by Annexin V-positivity and PI-negativity, while late apoptotic cells were calculated by Annexin V-positivity and PI-positivity.

Measurement of mitochonrial membrane potential $(\Delta \psi m)$ by flow cytometry analysis with JC-1 staining. To evaluate for the loss of mitochondrial membrane potential, SW1353 cells were stained with the fluorescent dye JC-1. JC-1 is a cationic dye that can be used as an indicator of mitochondrial potential, exhibits potential mitochondria-dependent accumulation and indicated by a fluorescence emission shift from green to red. Various times of millimeter wave radiation treatment were used. The cells $\left(1 \times 10^{6}\right)$ were resuspended after trypsin- 


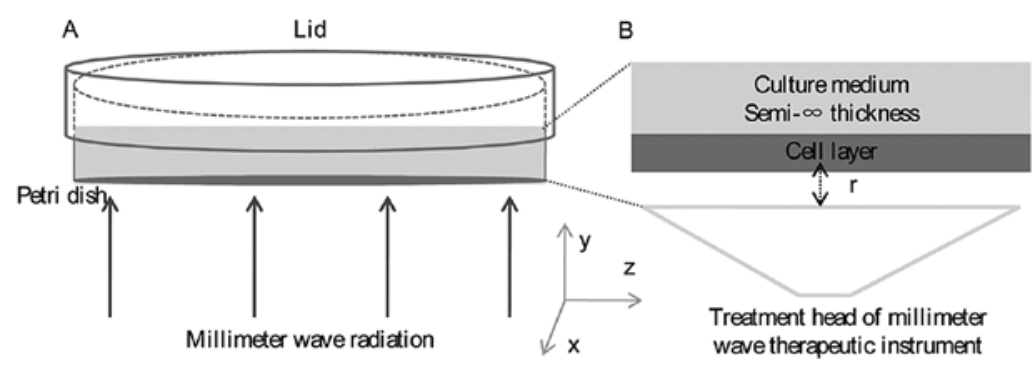

Figure 1. Millimeter wave radiation treatment method. (A) Schematic representation of millimeter wave radiation, far field exposure set-up used for investigating millimeter wave radiation induced in vitro effects on $35 \mathrm{~mm}$ Petri dish cell culture system. (B) Enlargement of the Petri dish showing all the dielectric interfaces through which millimeter wave radiation propagates. The multiple stratified dielectric system was used to model the reflection properties of cell systems cultured in the Petri dish.

ization in $1 \mathrm{ml}$ of medium and incubated with $10 \mu \mathrm{g} / \mathrm{ml}$ of JC-1 (Invitrogen) at $37^{\circ} \mathrm{C}$ for $30 \mathrm{~min}$. After JC-1 staining, green and red fluorescence emissions were analyzed by flow cytometry.

$R N A$ extraction and RT-PCR analysis. After various times of millimeter wave radiation treatment, total-RNA from the cells was isolated with TRIzol reagent (Invitrogen). Oligo(dt)primed RNA $(5 \mu \mathrm{g})$ was reverse transcribed with SuperScript II reverse transcriptase (Promega) according to the manufacturer's instructions. The obtained cDNA was used to determine the mRNA amount of Bax and Bcl-2 by PCR with TaqDNA polymerase (Fermentas). $\beta$-actin was used as an internal control. The primers used for amplification of $\mathrm{Bcl}-2$, Bax and $\beta$-actin transcripts are as follows: Bax $289 \mathrm{bp}$, forward, 5'-CTG ACA TGT TTT CTG ACG GC-3' and reverse, 5'-TCA GCC CAT CTT CTT CCA GA-3'; Bcl-2 310 bp, forward, 5'-CGA CTT CGC CGA GAT GTC CAG CCA G-3' and reverse, 5'-ACT TGT GGC CCA GAT AGG CAC CCA G-3'; GAPDH 532 bp, forward, 5'- AGG TCG GAG TCA ACG GAT TTG-3' and reverse, 5'- GTG ATG GCA TGG ACT GTG GT-3'.

Western blot analysis. SW1353 cells were cultured in $35 \mathrm{~mm}$ Petri dish at a concentration of $5 \times 10^{4}$ cells. After treated with millimeter wave radiation for 60 and $90 \mathrm{~min}$, and then cultured $24 \mathrm{~h}$. The treated cells were lysed with radio immunoprecipitation assay (RIPA) lysis buffer (Beyotime Biotechnology, China) containing $1 \mathrm{mM}$ phenylmethanesulfonyl fluoride (PMSF) (Beyotime Biotechnology), and extracts were quantified using the BCA protein assay. Protein $(20 \mu \mathrm{g})$ was resolved on a $12 \%$ SDS-polyacrylamide gel under reducing conditions using $110 \mathrm{~V}$ for $2 \mathrm{~h}$. After electrophoresis, the proteins were transferred to PVDF membranes in a Tris-glycine transfer buffer (48 $\mathrm{mM}$ Tris, $39 \mathrm{mM}$ glycine, $0.05 \% \mathrm{w} / \mathrm{v}$ SDS, $10 \% \mathrm{v} / \mathrm{v}$ methanol) using a semidry blotting system, detected with antibodies against Bcl-2, Bax and $\beta$-actin $(1: 1,000)$ overnight at $4^{\circ} \mathrm{C}$ with rocking. The membranes were washed in TBST, secondary horseradish peroxidase (HRP)-conjugated antibodies were added at 1:2,000 dilution for $2 \mathrm{~h}$ at room temperature. Detection was performed by enhanced chemiluminescenc (ECL) using a Western blotting luminol reagent (Santa Cruz Biotechnology) according to the manufacturer's instructions. Bands were then quantified by scanning densitometry (1708070 Molecular Imager ChemiDoc XRS system, Bio-Rad, USA). Protein concentrations were determined using the
Tocan 190 protein assay system and normalized to $\beta$-actin in the sample.

Analysis of caspase-9 and caspase-3 activation. SW1353 cells were cultured in $35 \mathrm{~mm}$ Petri dishes at a concentration of $5 \times 10^{4}$ cells and treated with millimeter wave radiation for 60 and $90 \mathrm{~min}$, and then cultured for $24 \mathrm{~h}$. The activities of caspase- 9 and caspase- 3 were determined by a colorimetric assay using the caspase- 9 and caspase- 3 activation kits (Invitrogen), following the manufacturer's instructions. The treated cells were lysed with the provided lysis buffer for $30 \mathrm{~min}$ on ice, centrifuged at $16,000 \mathrm{x} \mathrm{g}$ for $15 \mathrm{~min}$, and extracts were quantified using the BCA protein assay. Then, the protein $(100 \mu \mathrm{g})$ was incubated with the colorimetric tetrapeptides $(50 \mu \mathrm{l})$, Leu-Glu-His-Asp (LEHD)-p-nitroaniline (pNA) (specific substrate of caspase-9) or Asp-Glu-Val-Asp (DEAD)-pNA (specific substrate of caspase-3) at $37^{\circ} \mathrm{C}$ for $2 \mathrm{~h}$. The samples were read at $405 \mathrm{~nm}$ in an ELISA reader (EXL800, BioTek).

Observation of ultrastructural characteristics by transmission electron microscopy. The cell suspensions at $24 \mathrm{~h}$ of culture, after treatment with millimeter wave radiation for 60 and $90 \mathrm{~min}$, were centrifuged and the pellets were fixed with $3 \%$ glutaraldehyde and $1.5 \%$ paraformaldehyde solution $(\mathrm{pH} \mathrm{7.3)}$ at $4^{\circ} \mathrm{C}$ for $24 \mathrm{~h}$. The cell suspensions were then rinsed twice with phosphate-buffer solution (PBS) and post-fixed with $1 \%$ osmic acid and $1.5 \%$ potassium hexacyanoferrate (II) solution (pH 7.3) and incubated at $4^{\circ} \mathrm{C}$ for $2 \mathrm{~h}$, then the cell suspensions were dehydrated in a graded series of alcohol for $5 \mathrm{~min}$ each. The dehydrated pellets were embedded three times with propylene oxide for $1 \mathrm{~h}$ each and infiltrated with a resin/ propylene oxide mixture at 1:1 ratio for $2 \mathrm{~h}$ and then with resin only for $12 \mathrm{~h}$ at room temperature. The inclusion was made with Epoxide resin 618 and Araldite and the polymerization was performed at $60^{\circ} \mathrm{C}$ for $48 \mathrm{~h}$. Ultrathin sections $(80 \mathrm{~nm})$ were stained with uranyl acetate and counterstained with lead citrate for $5 \mathrm{~min}$. The stained ultrasections were examined with the H7650 transmission electron microscope (Hitachi, Japan).

Statistical analysis. Data were analyzed using the SPSS package for Windows (version 13.0). The quantitative data were expressed as mean \pm standard deviation (SD). Statistical analysis of the data was performed with Student's t-test and 


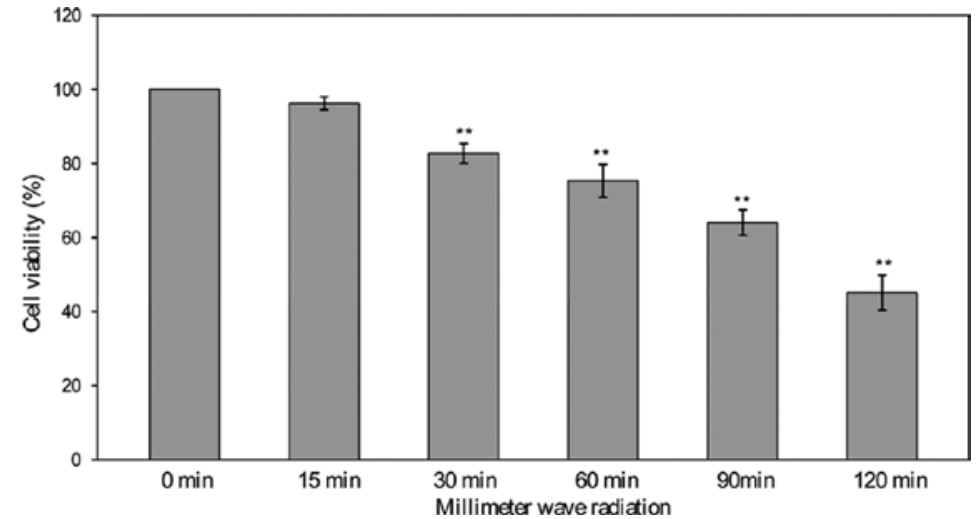

Figure 2. Effect of millimeter wave radiation on cell viability of SW1353 cells. Cells were treated for the indicated time of millimeter wave radiation. Cell viability was determined by the MTT assay. The data were normalized to the viability of untreated cells (100\%). Data are the average \pm SD (error bars). ${ }^{* *} \mathrm{P}<0.01$, significant vs. untreated cells.
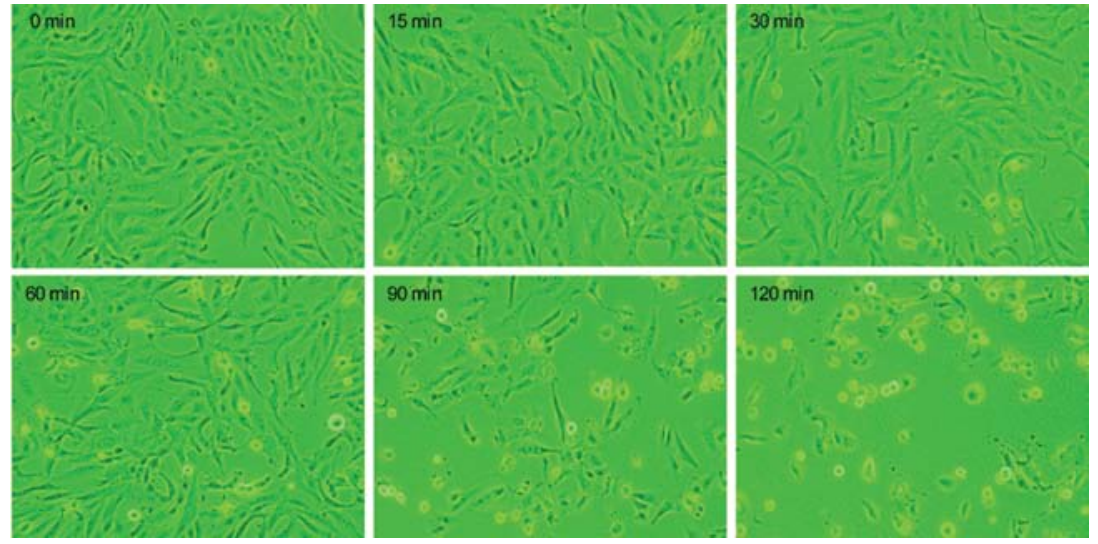

Figure 3. Effect of millimeter wave radiation on the morphological changes of SW1353 cells (x100). SW1353 cells were treated for 15, 30, 60,90 and 120 min with millimeter wave radiation, and then cultured for $24 \mathrm{~h}$, the morphological changes were observed using phase-contrast microscopy.
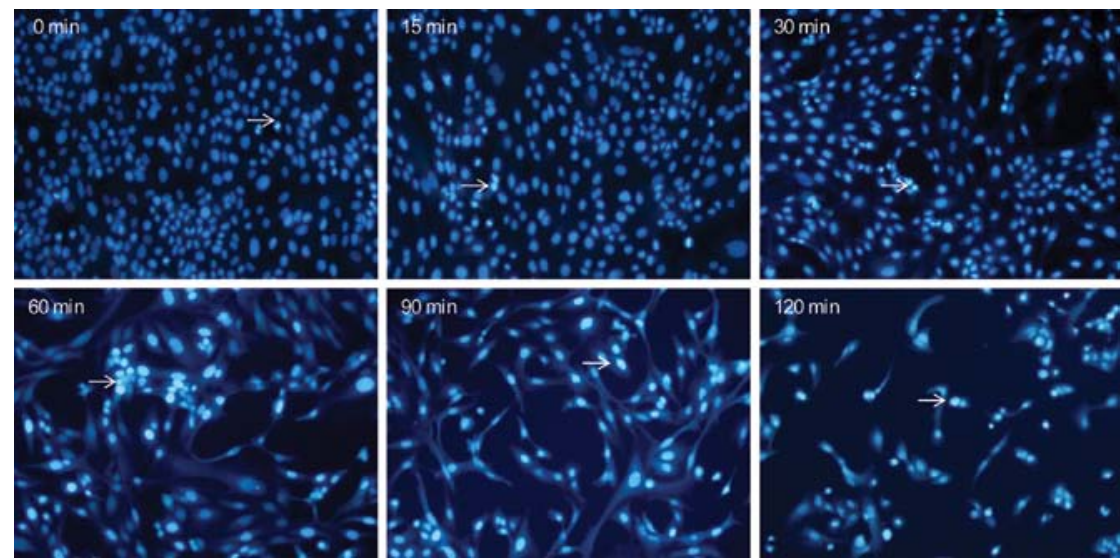

Figure 4. Effect of millimeter wave radiation on apoptosis of SW1353 cells (x100). Determination of apoptosis in SW1353 cells was observed using Hoechst 33258 staining after millimeter wave radiation treatment. Arrows $(\rightarrow)$ indicate typical apoptotic cells.

ANOVA. Differences with P-values $<0.05$ were considered statistically significant.

\section{Results}

Millimeter wave radiation inhibits the viability of SW1353 cells. The effect of millimeter wave radiation on the viability of SW1353 cells was determined by MTT assay. The cells treated with millimeter wave radiation for $30 \mathrm{~min}$ $(82.75 \pm 2.66 \%), 60 \min (75.36 \pm 4.42 \%), 90 \min (64.06 \pm 3.41 \%)$ and $120 \mathrm{~min}(45.13 \pm 4.72 \%)$ time-dependently reduced cell viability compared to untreated cells $(100 \pm 0.00 \%)(\mathrm{P}<0.01)$ (Fig. 2). This indicates that millimeter wave radiation inhibits cell viability in a time-dependent manner. 
A
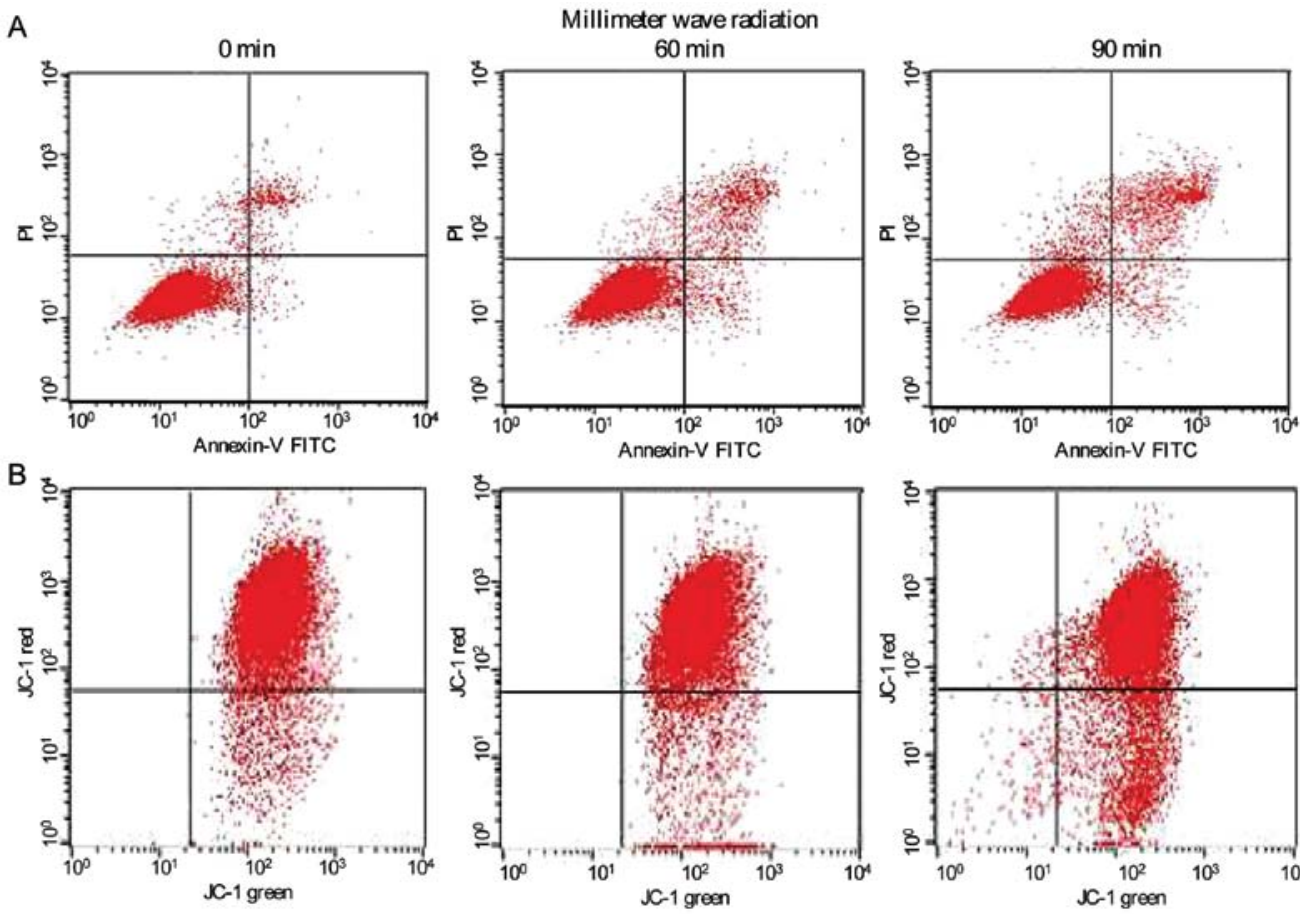

$c$

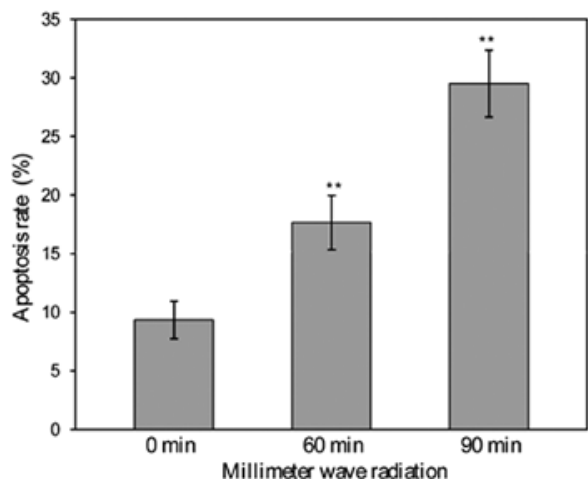

D

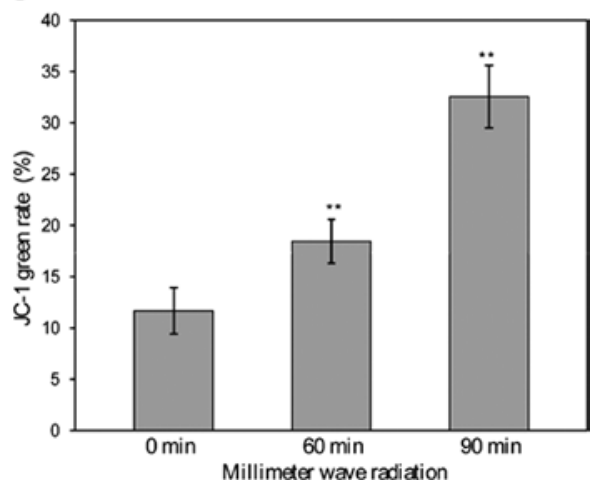

Figure 5. Effect of millimeter wave radiation on the apoptosis and the loss of mitochondrial membrane potential of SW1353 cells. (A) After treatment with millimeter wave radiation, SW1353 cells were collected and stained with Annexin V/PI followed by FACS analysis. (B) SW1353 cells were treated with millimeter wave radiation and stained with JC-1. The mean JC-1 fluorescence intensity was detected using FACS analysis. (C) Quantification of apoptosis in SW1353 cells by FACS analysis. The data shown are averages \pm SD (error bars). ${ }^{* *} \mathrm{P}<0.01$, significant vs. untreated cells. (D) Quantification of the loss of mitochondrial membrane potential in SW1353 cells by FACS analysis. The data shown are the average \pm SD (error bars). ${ }^{* *} \mathrm{P}<0.01$, significant vs. untreated cells.

Millimeter wave radiation induces SW1353 cell morphologic changes. The effect of millimeter wave radiation on SW1353 cell morphologic changes was evaluated by phase-contrast microscopy, since the cells morphology in culture is indicative of the health status. Untreated SW1353 cells appeared as densely disorganized multilayers, whereas after treatment with millimeter wave radiation for 15, 30, 60, 90 and $120 \mathrm{~min}$, and cultured for $24 \mathrm{~h}$ (Fig. 3), a number of the cells became shrunken and detached from each other or floated in the medium, suggesting that millimeter wave radiation inhibits the growth of SW1353 cells.

Millimeter wave radiation mediates apoptosis of SW1353 cells. To further verify whether the cell-growth suppressive effect of millimeter wave radiation is due to apoptosis, the cells were stained using Hoechst 33258 after treatment. Hoechst 33258 staining displayed condensed, crescent-aggregated, segmented or fragmented nuclei characteristic of apoptotic nuclei. The results indicated that normal cells displayed a weak fluorescence while apoptotic cells showed increased bright fluorescence and typical apoptotic phenomena. Typical apoptotic characteristics such as nuclear condensation were observed after millimeter wave radiation exposure (Fig. 4). To investigate that millimeter wave radiation-induced apoptosis of SW1353 cells, we examined the millimeter wave radiation pro-apoptotic activity in SW1353 cells with Annexin V/PI staining followed by FACS analysis. LL indicates viable cells (Annexin V/PI double-negative population), LR or UR represents cells undergoing early (Annexin V-positive/PI-negative) or late apoptosis (Annexin V/ PI double-positive population), respectively (Fig. 5A). The percentages of cell apoptosis including the early and late apoptotic cell treatment with $60 \mathrm{~min}(17.66 \pm 2.32 \%)$ and $90 \mathrm{~min}$ $(29.51 \pm 2.86 \%)$ of millimeter wave radiation was significantly higher than untreated cells $(9.36 \pm 1.60 \%)(\mathrm{P}<0.01)($ Fig. $5 \mathrm{C})$. 


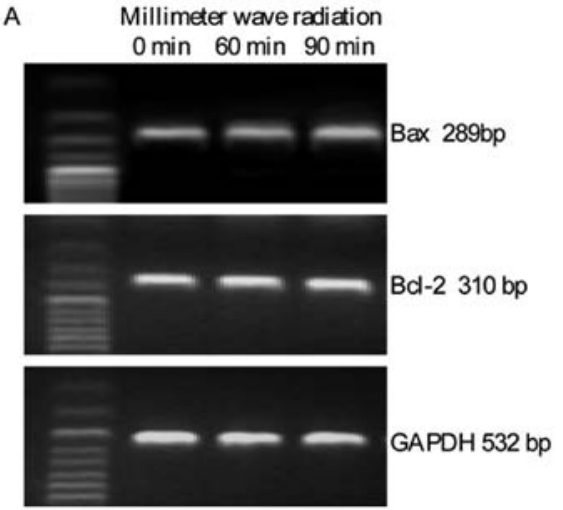

B

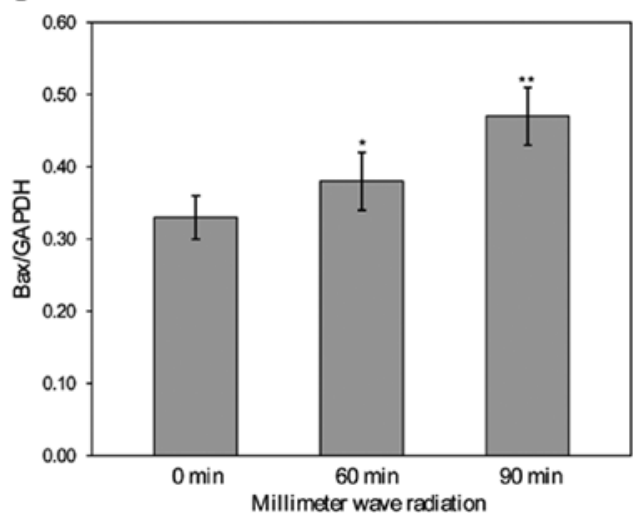

C

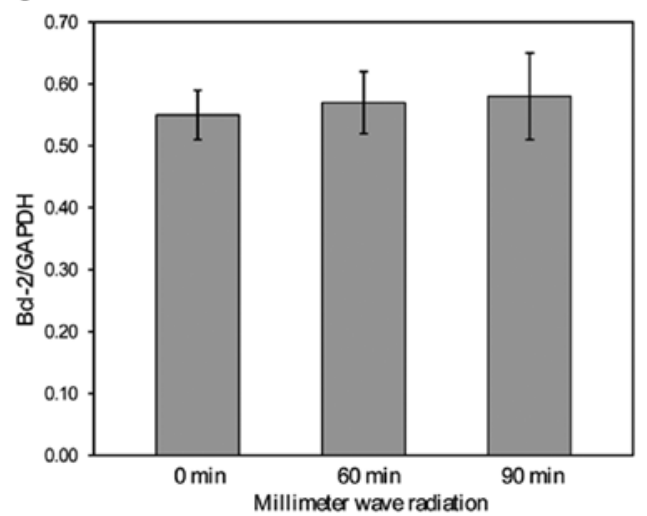

Figure 6. Effect of millimeter wave radiation on the mRNA expression of Bax and Bcl-2 in SW1353 cells. (A) The mRNA expression of Bax and Bcl-2 in millimeter wave radiation-treated and untreated cells were determined by RT-PCR. $\beta$-actin was used as the internal control for the RT-PCR assays. Quantification of RT-PCR analysis, the data shown are the average \pm SD (error bars). ${ }^{*} \mathrm{P}<0.05 ;{ }^{* * *} \mathrm{P}<0.01$, significant vs. untreated cells. (B) The mRNA expression of Bax in millimeter wave radiation-treated and untreated cells. (C) The mRNA expression of Bcl-2 in millimeter wave radiation-treated and untreated cells.

These data demonstrate that millimeter wave radiation induced cell apoptosis in a time-dependent manner.

Millimeter wave radiation induces the loss of mitochondrial potential $(\Delta \psi m)$. To confirm the pro-apoptotic function of millimeter wave radiation, investigated the effect of millimeter wave radiation on the loss of mitochondrial potential $(\Delta \psi \mathrm{m})$, a typical feature of apoptosis. After millimeter wave radiation treatment, we used FACS analysis with JC-1 staining to examine the change in mitochondrial membrane potential.

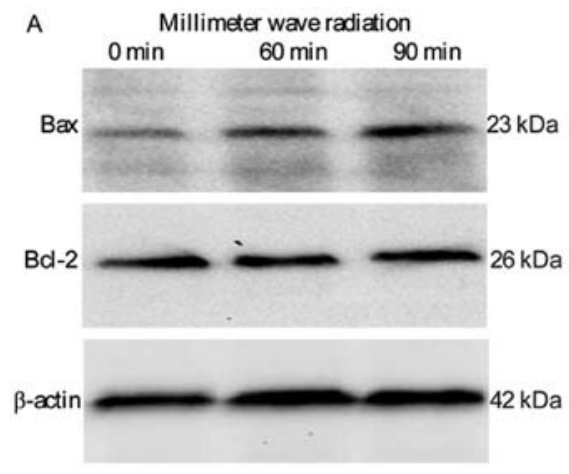

B

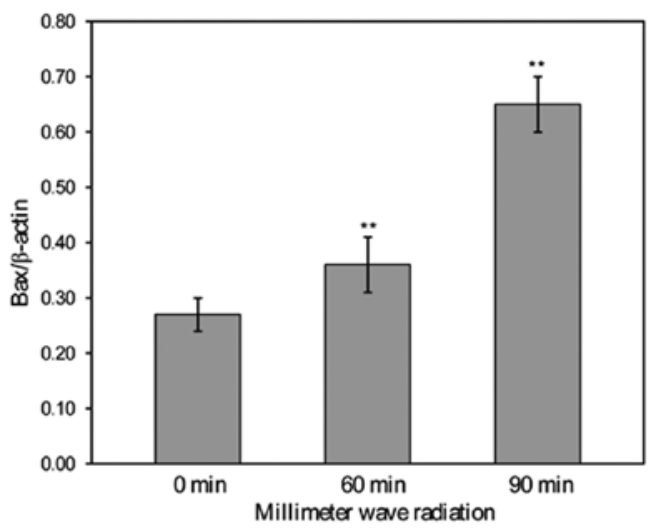

C

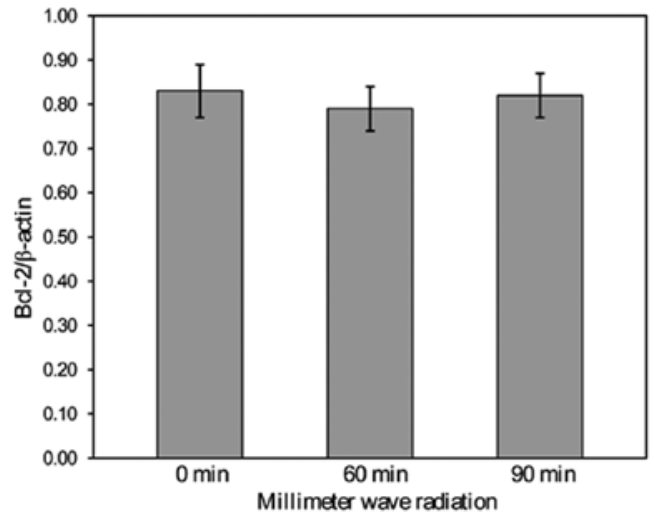

Figure 7. Effect of millimeter wave radiation on the protein expression levels of Bax and Bcl-2 in SW1353 cells. (A) The protein expression levels of Bax and Bcl- 2 were analyzed by Western blotting. $\beta$-actin was used as the internal control for the Western blot assays. Quantification of Western blotting, the data shown the average \pm SD (error bars). ${ }^{* *} \mathrm{P}<0.01$, significant vs. untreated cells. (B) The protein expression levels of Bax in millimeter wave radiationtreated and untreated cells. (C) The protein expression levels of Bcl-2 in millimeter wave radiation-treated and untreated cells.

JC-1 selectively enters into mitochondria and accumulates in mitochondria, and then forms J-aggregates with intense red fluorescence (590 nm, FL-2) in healthy cells; whereas JC-1 does not accumulate in mitochondria due to the loss of mitochondrial membrane potential, but JC-1 may remain in the cytoplasm in monomeric form showing green fluorescence (525 nm, FL-1). JC-1 fluorescence was shifted from a JC-1green-bright/JC-1-red-bright signal in untreated SW1353 cells to a JC-1-green-bright/JC-1-red-dim signal in cells treated with millimeter wave radiation in a time-dependent manner, the percentages of JC-1-green-bright cells with $60 \mathrm{~min}(18.45 \pm 2.14 \%)$ and $90 \mathrm{~min}(32.56 \pm 3.05 \%)$ of milli- 

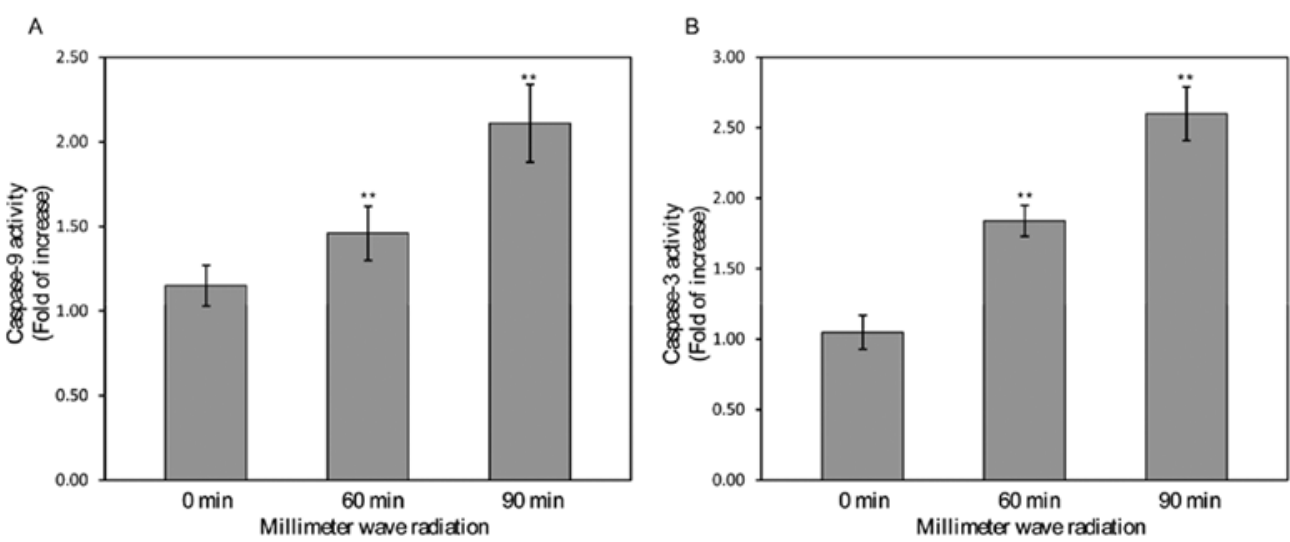

Figure 8. Effect of millimeter wave radiation on the activity of caspases in SW1353 cells. SW1353 cells were treated with the indicated time of millimeter wave radiation. Caspase-9 and caspase-3 activities were determined by a colorimetric assay. The data were normalized to the caspase activities within untreated cells and presented as fold of control. The data shown are the average $\pm \mathrm{SD}$ (error bars). ${ }^{* *} \mathrm{P}<0.01$, significant vs. untreated cells. (A) The activity of caspase- 9 in millimeter wave radiation-treated and untreated SW1353 cells. (B) The activity of caspase-3 in millimeter wave radiation-treated and untreated SW1353 cells.
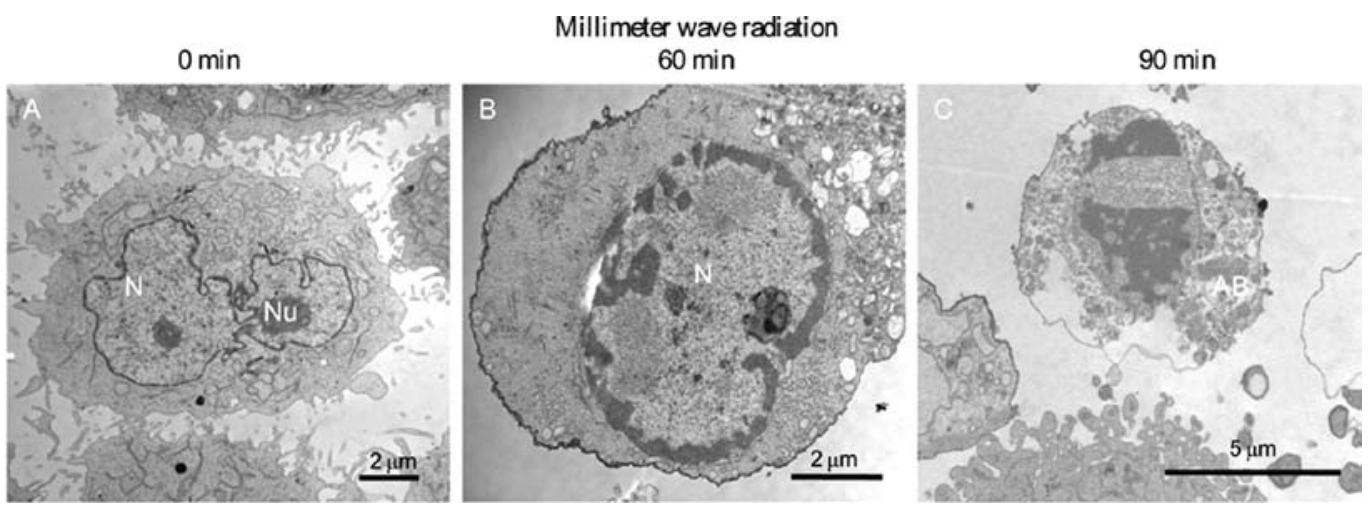

Figure 9. Effect of millimeter wave radiation on the ultrastructural changes of SW1353 cells. (A) The untreated SW1353 cells in which some mitochondria and rough endoplasmic reticulum were observed; also the nucleus contains either euchromatin or heterochromatin (original magnification, x10,000). (B) The cells treated with millimeter wave radiation showed typical apoptotic phenomena, chromosome was condensed into a semilunar shape clinging to the cellular membrane and the karyotheca (original magnification, x15,000). (C) Apoptotic bodies were observed in SW1353 cells with millimeter wave treatment (original magnification, $\mathrm{x} 6,000)$. $\mathrm{N}$, nucleus; $\mathrm{Nu}$, nucleoli; $\mathrm{AB}$, apoptotic body.

meter wave radiation was significantly higher than untreated cells $(11.68 \pm 2.26 \%)(\mathrm{P}<0.01)$, indicating millimeter wave radiation-induced loss of mitochondrial membrane potential in SW1353 cells (Fig. 5B and D).

Millimeter wave radiation regulates the expression of proapoptotic Bax and anti-apoptotic Bcl-2. Bcl-2 family proteins including pro-apoptotic member $\mathrm{Bax}$ and anti-apoptotic member Bcl-2 are central in regulation of mitochondrionmediated apoptosis. To further study the mechanism of millimeter wave radiation on cell apoptosis, the mRNA and protein expression of Bax and Bcl-2 in millimeter wave radiation-treated cells were examined by RT-PCR and Western blotting, respectively. The results of the RT-PCR assay showed that millimeter wave radiation treatment profoundly increased Bax mRNA expression in SW1353 cells compared to untreated cells $(\mathrm{P}<0.05, \mathrm{P}<0.01)$, but did not significantly change Bcl-2 mRNA expression (Fig. 6); and the pattern of protein expression of $\mathrm{Bax}$ and $\mathrm{Bcl}-2$ was similar to their respective mRNA levels (Fig. 7). This suggests that millimeter wave radiation induces cell apoptosis via the upregulation of Bax/Bcl-2 ratio.
Millimeter wave radiation inhibits the activation of caspase-9 and caspase-3. The mitochondrial membrane permeabilization results in the release of numerous apoptogenic proteins from the mitochondria triggering the activation of caspase- 9 and caspase-3, and eventually inducing apoptosis. To investigate the downstream effectors in the apoptotic signaling pathway, the activation of caspase- 9 and caspase- 3 was detected by a colorimetric assay. Millimeter wave radiation treatment significantly and time-dependently induced activation of caspase-9 and caspase-3 in SW1353 cells compared to untreated cells $(\mathrm{P}<0.01)$ (Fig. 8). Taken together, these results suggest that millimeter wave radiation promotes cell apoptosis via the mitochondrion-dependent pathway.

Millimeter wave radiation induces SW1353 cell ultrastructural changes. The ultrastructural characteristics of SW1353 cells were revealed by TEM observation of the ultrathin sections. The untreated cells had generally irregular contours but their surface was characterized by many corrugations and microvilli-like structures, and the presence of some cytoplasm which contained a relatively abundant number of mitochondria often with large dimensions; nucleus of control 
SW1353 cells showed indentation or lobate morphology occupying an extended portion of the cytoplasm, one or two nucleoli were found (Fig. 9A). In contrast, the cells treated with millimeter wave radiation showed typical apoptotic phenomena. The nucleus decreased in size, karyotheca was crumpled, karyoplasm was concentrated, chromosome was condensed into a semilunar shape clinging to the cellular membrane and the karyotheca, and apoptotic bodies were observed when ruptured to the nuclear margin and chromatin was condensed (Fig. 9B and C). In the 90 min group, there were more apoptotic cells and apoptotic bodies than in the 60 min group.

\section{Discussion}

Our study demonstrates that millimeter wave radiation induces loss of mitochondrial membrane potential, up-regulates the expression of proapoptotic proteins Bax, caspase-9 and caspase-3, but did not significantly change anti-apoptotic Bcl-2. Hence, millimeter wave radiation induces SW1353 cell apoptosis by affecting the ratio of $\mathrm{Bax} / \mathrm{Bcl}-2$.

Millimeter wave radiation can be used as a monotherapy or in combination with other treatment methods to reduce the side effects and increase the efficacy of chemotherapy in cancer treatment $(19,20)$. Though some studies have in most cases qualitative character, recently, quantitative evidence has been reported on the physiologic mechanism of millimeter wave radiation on the human body that could account for many in vivo its biological effects such as anticancer activity in different tumoral cell culture systems $(21,22)$. In order to test SW1353 cell apoptosis by millimeter wave radiation, we determined whether millimeter wave radiation can enhance SW1353 cell activity in the apoptotic pathway under our experimental conditions used for increasing the efficacy of radiotherapy in the treatment of cancer.

Here we report that millimeter wave radiation reduces the viability and inhibits growth of SW1353 cells in a timedependent manner. Furthermore, we demonstrated that these effects on SW1353 cells result from the induction of apoptosis by millimeter wave radiation.

Tumor cells are characterized by a basic pathology of an unregulated increase in cell proliferation and/or a reduction in cell apoptosis. Moreover, disrupted apoptosis contributes to drug resistance of tumor cells, which has become an efficient method in cancer treatment (23). Apoptosis is triggered by two different pathways, the intrinsic involving the mitochondria, activated by modulators within the cell itself; and the extrinsic involving death receptors, which respond mainly to extracellular stimuli $(24,25)$. Both pathways can eventually lead to the activation of caspases and nucleases, resulting in cell apoptosis. Mitochondrial outer membrane permeabilization (MOMP), a key commitment step in the induction of cellular apoptosis, is often required for activation of the caspase proteases $(26,27)$. It is important that the electrochemical gradient across the mitochondrial membrane collapses during the process of MOMP (28). Hence, the loss of mitochondrial membrane potential is a hallmark for apoptosis, our data clearly indicated that treatment with millimeter wave radiation enhances apoptosis and leads to a collapse of mitochondrial membrane potential in SW1353 cells.
Bcl-2 family proteins regulate mitochondrion-dependent apoptosis by influence on the permeability of MOM (29). Apoptosis-associated MOMP is known to require pro-apoptotic Bax-like proteins (in regulation of the formation of pores in the mitochondria) and anti-apoptotic Bcl-2-like proteins (functionally distinct from their role in mitochondrial morphogenesis) (30). Therefore, the ratio of $\mathrm{Bax} / \mathrm{Bcl}-2$ is a critical for determining the release of many apoptogenic proteins from the mitochondrial intermembrane space to drive the caspase cascade (31). Caspases are the key proteins that modulate the apoptotic response. Caspase- 3 is activated by an initiator caspase such as caspase-9 during mitochondrion-mediated apoptosis, which is a key executioner of apoptosis $(32,33)$.

In this study, we demonstrated that millimeter wave radiation time-dependently up-regulates Bax mRNA expression, but did not significantly change Bcl-2 mRNA expression in SW1353 cells. This indicates that millimeter wave radiation induces apoptosis by affecting the ratio of $\mathrm{Bax} / \mathrm{Bcl}-2$ at transcriptional level. We further studied the role of millimeter wave radiation on the expression of proteins involved in the mitochondrial pathway. The results showed that treatment with millimeter wave radiation enhances Bax, caspase- 9 and caspase-3 protein expression, which is in accordance with the pattern of their mRNA expression.

In summary, the present study demonstrates that millimeter wave radiation significantly reduced the viability and inhibited the growth of SW1353 cells. Our data suggest that a reduction in SW1353 cell apoptosis occurs, at least in part, through affecting the ratio of Bax/Bcl-2 by millimeter wave radiation. However, further experimental and theoretical studies are needed to clarify the biochemical effects of millimeter wave radiation induced apoptosis on tumor cellular systems. As a non-pharmaceutical and non-invasive therapy regimen, millimeter wave radiation is economic in terms of system manufacturing, accessibility to patients and has potential of further development into a novel method in treating onclogical diseases.

\section{Acknowledgements}

This study was supported by the Natural Science Foundation of Fujian Province (Grant nos. 2011J05074 and 2011J05076) and the 2008 Fujian Province Small Creations and Projects (no. 1).

\section{References}

1. Szabo I, Kappelmayer J, Alekseev SI and Ziskin MC: Millimeter wave induced reversible externalization of phosphatidylserine molecules in cells exposed in vitro. Bioelectromagnetics 27: 233-244, 2006.

2. Alekseev SI and Ziskin MC: Influence of blood flow and millimeter wave exposure on skin temperature in different thermal models. Bioelectromagnetics 30: 52-58, 2009.

3. Radzievsky AA, Gordiienko OV, Alekseev S, Szabo I, Cowan A and Ziskin MC: Electromagnetic millimeter wave induced hypoalgesia: frequency dependence and involvement of endogenous opioids. Bioelectromagnetics 29: 284-295, 2008.

4. Beneduci A, Chidichimo G, Tripepi S and Perrotta E: Transmission electron microscopy study of the effects produced by wide-band low-power millimeter waves on MCF-7 human breast cancer cells in culture. Anticancer Res 25: 1009-1013, 2005.

5. Beneduci A: Evaluation of the potential in vitro antiproliferative effects of millimeter waves at some therapeutic frequencies on RPMI 7932 human skin malignant melanoma cells. Cell Biochem Biophys 55: 25-32, 2009. 
6. Teppone M and Avakyan R: Extremely high-frequency therapy in oncology. J Altern Complement Med 16: 1211-1216, 2010.

7. Logani MK, Szabo I, Makar V, Bhanushali A, Alekseev S and Ziskin MC: Effect of millimeter wave irradiation on tumor metastasis. Bioelectromagnetics 27: 258-264, 2006.

8. Maeda K, Maeda T and Qi Y: In vitro and in vivo induction of human LoVo cells into apoptotic process by non-invasive microwave treatment: a potentially novel approach for physical therapy of human colorectal cancer. Oncol Rep 11: 771-775, 2004.

9. Caraglia M, Marra M, Mancinelli F, et al: Electromagnetic fields at mobile phone frequency induce apoptosis and inactivation of the multi-chaperone complex in human epidermoid cancer cells J Cell Physiol 204: 539-548, 2005.

10. Soriano ME and Scorrano L: The interplay between BCL-2 family proteins and mitochondrial morphology in the regulation of apoptosis. Adv Exp Med Biol 687: 97-114, 2010.

11. Chen $\mathrm{C}$, Zhou H, Wei $\mathrm{F}$, et al: Increased levels of hypoxiainducible factor- $1 \alpha$ are associated with Bcl-xL expression, tumor apoptosis, and clinical outcome in chondrosarcoma. J Orthop Res 29: 143-151, 2011.

12. Li Z and Xing D: Mitochondrial pathway leading to programmed cell death induced by aluminum phytotoxicity in Arabidopsis. Plant Signal Behav 5: 1660-1662, 2010.

13. Lu HF, Chie YJ, Yang MS, et al: Apigenin induces caspase-dependent apoptosis in human lung cancer A549 cells through Bax- and Bcl-2-triggered mitochondrial pathway. Int J Oncol 36: 1477-1484, 2010.

14. Autret A and Martin SJ: Emerging role for members of the Bcl-2 family in mitochondrial morphogenesis. Mol Cell 36: 355-363, 2009.

15. Martinou JC and Youle RJ: Mitochondria in apoptosis: bcl-2 family members and mitochondrial dynamics. Dev Cell 21: 92-101, 2011

16. Llambi F and Green DR: Apoptosis and oncogenesis: give and take in the BCL-2 family. Curr Opin Genet Dev 21: 12-20, 2011.

17. Beneduci A, Chidichimo G, De Rose R, Filippelli L, Straface SV and Venuta S: Frequency and irradiation time-dependent antiproliferative effect of low-power millimeter waves on RPMI 7932 human melanoma cell line. Anticancer Res 25: 1023-1028, 2005.

18. Chidichimo G, Beneduci A, Nicoletta M, et al: Selective inhibition of tumoral cells growth by low power millimeter waves. Anticancer Res 22: 1681-1688, 2002.

19. Logani MK, Bhanushali A, Anga A, Majmundar A, Szabo I and Ziskin MC: Combined millimeter wave and cyclophosphamide therapy of an experimental murine melanoma. Bioelectromagnetics 25: 516-523, 2004
20. Pletnev SD: The use of millimeter band electromagnetic waves in clinical oncology. Crit Rev Biomed Eng 28: 573-587, 2000

21. Radzievsky AA, Gordiienko OV, Szabo I, Alekseev SI and Ziskin MC: Millimeter wave-induced suppression of B16 F10 melanoma growth in mice: Involvement of endogenous opioids. Bioelectromagnetics 25: 466-473, 2004.

22. Beneduci A, Chidichimo G, Tripepi S, Perrotta E and Cufone F: Antiproliferative effect of millimeter radiation on human erythromyeloid leukaemia cell line K562 in culture: Ultrastructural- and metabolic-induced changes. Bioelectrochemistry 70: 214-220, 2007.

23. Gordon EM and Hall FL: Noteworthy clinical case studies in cancer gene therapy: tumor-targeted Rexin-G advances as an efficacious anti-cancer agent. Int J Oncol 36: 1341-1353, 2010.

24. Kim SH, Kim SH, Lee SC and Song YS: Involvement of both extrinsic and intrinsic apoptotic pathways in apoptosis induced by genistein in human cervical cancer cells. Ann NY Acad Sci 1171: 196-201, 2009.

25. Parsons MJ and Green DR: Mitochondria in cell death. Essays Biochem 47: 99-114, 2010.

26. Vaux DL: Apoptogenic factors released from mitochondria. Biochim Biophys Acta 1813: 546-550, 2011.

27. Jourdain A and Martinou JC: Mitochondrial outer-membrane permeabilization and remodelling in apoptosis. Int J Biochem Cell Biol 41: 1884-1889, 2009.

28. Wang $\mathrm{C}$ and Youle RJ: The role of mitochondria in apoptosis. Annu Rev Genet 43: 95-118, 2009.

29. Lindsay J, Esposti MD and Gilmore AP: Bcl-2 proteins and mitochondria - specificity in membrane targeting for death. Biochim Biophys Acta 1813: 532-539, 2011.

30. García-Sáez AJ, Fuertes G, Suckale J and Salgado J: Permeabilization of the outer mitochondrial membrane by Bcl-2 proteins. Adv Exp Med Biol 677: 91-105, 2010.

31. Ganesan V, Perera MN, Colombini D, Datskovskiy D, Chadha K and Colombini M: Ceramide and activated Bax act synergistically to permeabilize the mitochondrial outer membrane. Apoptosis 15: 553-562, 2010.

32. Islam S, Islam N, Kermode T, et al: Involvement of caspase-3 in epigallocatechin-3-gallate-mediated apoptosis of human chondrosarcoma cells. Biochem Biophys Res Commun 270: 793-797, 2000.

33. Caroppi P, Sinibaldi F, Fiorucci L and Santucci R: Apoptosis and human diseases: mitochondrion damage and lethal role of released cytochrome $\mathrm{C}$ as proapoptotic protein. Curr Med Chem 16: 4058-4065, 2009. 